\title{
Application of response surface methodology for optimization of medium components for the production of secondary metabolites by Streptomyces diastatochromogenes KX852460
}

\author{
Taswar Ahsan ${ }^{1}$, Jianguang Chen ${ }^{1}$, Yuanhua Wu ${ }^{1 *}$ and Muhammad Irfan²
}

\begin{abstract}
A bioactive strain Streptomyces diastatochromogenes KX852460 was selected for the production of secondary metabolites to control the target spot disease on tobacco leaves, caused by the Rhizoctonia solani AG-3. Peanut meal, soluble starch, $\mathrm{NaCl}$, yeast extract, and ammonium sulphate were identified the best ingredient for high antifungal activity of S. diastatochromogenes KX852460 against the R. solani AG-3. For the improved production of secondary metabolites, central composite design of response surface methodology was applied in submerged fermentation. The best concentrations of ingredients were peanut meal $4.88 \%$, soluble starch $4.40 \%, \mathrm{NaCl} 0.52 \%$, yeast extract $0.47 \%$, and ammonium sulphate $0.0360 \%$. Study of metabolism changes in the submerged fermentation process was analyzed. Level of the reducing sugar increased, as the total sugar consumed. Amino nitrogen and total sugar decrease tendency, which indicated the growth of bacteria in submerged fermentation batch. Production of secondary and other metabolites influenced the $\mathrm{pH}$ of the fermentation batch.
\end{abstract}

Keywords: Streptomyces diastatochromogenes, Bioactive compounds, RSM, Fermentation

\section{Introduction}

Rhizoctonia solani is the major soil borne pathogen and the causal agent of several kinds of diseases in plants throughout the world, and have destructive impacts on the production of tobacco. In the Liaoning province of China in 2006 target spot disease on tobacco leaves was investigated and analyzed that $R$. solani AG-3 was the causal agent of this disease (Wu et al. 2012). Biological control is most potent practice against the $R$. solani, even though environmental stresses impact on efficacies (dos Reis Almeida et al. 2007). In agriculture for the disease management of crops, production of ecofriendly agronomic antibiotic from nature is a growing task. Several

\footnotetext{
*Correspondence: wuyh7799@163.com

1 Department of Plant Pathology, Plant Protection College, Shenyang Agricultural University, Shenyang, People's Republic of China Full list of author information is available at the end of the article
}

actinomycetes species are the source of antibiotic (Clardy et al. 2006). In pharmaceutical products Streptomyces have a big part, and similarly agricultural antibiotics are produce by them (Demain and Sanchez 2009; ElMehalawy et al. 2005).

Medium composition and fermentation conditions may cause effects on the production of secondary metabolites from the Streptomyces. In the yield of secondary metabolites these parameters have a key role (Al-Hulu 2013). Minor variations in the composition of fermentation media, can be influenced on the yield and as well as on the metabolic profile of the microbe (Scherlach and Hertweck 2009). By fermentation production of enzymes and growth of microbes, directly related to the medium composition and conditions. Optimization of these parameters became a significant process. To optimize these parameters for the fermentation, several statics approaches are widely utilized (Kumar et al. 2016). 
Optimized nutrient parameters not only cause to boost $20 \%$ of the antifungal efficacies, however also understand its composition (Gao et al. 2016).

Response surface methodology is very beneficial tool to optimize numerous parameters of trails, to find relativeness among the factors, to find the best combination of parameters and prediction of responses. For the optimization of microbial products this method extensively used (Grahovac et al. 2014; Kong et al. 2014). For the optimization of important fermentation parameters several types of designs are accessible, in optimization process central composite design (CCD) is one of the most useful designs (Nouby et al. 2009). In current study an effort has been made to produce antibiotic by Streptomyces diastatochromogenes KX852460, using the central composite design of response surface methodology to improve the antifungal activity by optimizing the nutrient components in submerged fermentation.

\section{Materials and methods Microorganism}

Streptomyces strain TA1123 was isolated and identified as Streptomyces diastatochromogenes (GenBank Accession Number KX852460) on the base of morphological, biochemical and $16 \mathrm{~S}$ ribosomal RNA gene sequence (Ahsan et al. 2017a) and submitted to Chinese general microbial collection center (CGMCC4.7384) (Ahsan et al. 2017b). R. solani AG-3 (Gene bank accession number of KX852461, Chinese general microbial collection center CGMCC3.18223) was isolated from infected tobacco leaves and identified through molecular techniques (Ahsan et al. 2017b).

\section{Inoculum development}

Inoculum was prepared as described in our earlier reports (Ahsan et al. 2017b). Briefly, after the development of spores of Streptomyces strain KX852460 on Gause's synthetic medium agar plates, two spore cakes $(5 \mathrm{~mm})$ were used to inoculate the fermentation medium for the production of secondary metabolites.

\section{Mode of fermentation}

Submerged fermentation by $S$. diastatochromogenes KX852460 was carried out in $250 \mathrm{ml}$ Erlenmeyer flask containing $55 \mathrm{ml}$ of medium. The medium comprised of $(\mathrm{g} / \mathrm{l})$ soluble starch 47.0, Yeast extract 3.0, peanut meal 22.0, $\left(\mathrm{NH}_{4}\right)_{2} \mathrm{SO}_{4} 2.7, \mathrm{NaCl} 2.7, \mathrm{CaCo}_{3}, \mathrm{pH} 6.8$ was sterilized at $121{ }^{\circ} \mathrm{C}, 15 \mathrm{lbs}$ for $15 \mathrm{~min}$. After sterilization, the medium was allowed to cool at room temperature and inoculated with $7 \%$ suspension of $S$. diastatochromogenes and incubated at $30{ }^{\circ} \mathrm{C}$ with shaking speed of $165 \mathrm{rpm}$ for $96 \mathrm{~h}$. After the completion of fermentation, the culture filtrate was assessed for antifungal activity (Ahsan et al. 2017a).
Selection of the most significant fermentation parameters

Peanut meal and soluble starch were used as carbon and nitrogen sources, yeast added as additional nutrient, while others were kept at original concentrations. Select the most significant parameters by using the single variable procedure. Other microelements were including $\mathrm{NaCl}(0,0.2,0.4,0.6,0.8,1,1.2$, and $1.4 \%), \mathrm{ZnSO}_{4}(0$, 001, 0.01 and $0.1 \%), \mathrm{FeSO}_{4}(0,0.0005,0.001,0.0015$ and $0.002 \%),\left(\mathrm{NH}_{4}\right)_{2} \mathrm{SO}_{4}(0,0.2,0.4,0.6,0.8,1,1.2$ and $1.4 \%)$, $\mathrm{CuSO}_{4}(0,0.001,0.01$ and $0.1 \%), \mathrm{CaCO}_{3}(0,0.3,0.6,0.9$, and $1.2 \%), \mathrm{MgSO}_{4} \cdot 7 \mathrm{H}_{2} \mathrm{O}(0,0.001,0.01$ and $0.1 \%), \mathrm{MnCl}_{2}$ $(0,0.01,0.02,0.03$ and $0.04 \%), \mathrm{ZnSO}_{4}(0,0.001,0.01$ and $0.1 \%)$ and $\mathrm{KH}_{2} \mathrm{PO}_{4}(0,0.04,0.08,0.12$ and 0.16$)$, were added each nutrient to the medium, and antifungal activity was determined by oxford cup method, after $96 \mathrm{~h}$ of inoculation under shaking at $165 \mathrm{rpm}$ at $30{ }^{\circ} \mathrm{C}$.

\section{Experimental design for optimization of nutrient medium} In current study a central composite design (CCD) of five-factor-three-level was used, demanding 32 trials. The fractional factorial design comprises of nine factorial points, fourteen center points, and nine axial points with five parameters. The parameters and their levels used for the optimization of fermentation broth for the production of secondary metabolites was: $\mathrm{X}_{1}$ : peanut meal (0-12 ml\%), $X_{2}$ : soluble starch (0-12\%), $X_{3}: \mathrm{NaCl}$ $(0-1.2 \%), \mathrm{X}_{4}$ : yeast $(0-1.2 \%)$, and $\mathrm{X}_{5}$ : ammonium sulfate (0.00-0.12\%) (Table 1). Contour plots were generated to demonstrate the key and interactive impact between the independent variables and dependent variables. On the base of the ridge maxima analysis and canonical analysis, the optimal mishmash of the factors can be demonstrated, by employing the optimization function of the MINITAB 14 software. In the software response optimizer tool determined the optimal value for maximum antimicrobial activity.

\section{Metabolic profile in the fermentation batch}

Using the dinitrosalicylic acid, reducing sugar in the fermentation batch was measured (Miller 1959) and total sugars were measured by Phenol-sulphuric acid method (Dubois et al. 1956). Amino nitrogen was determined, using ninhydrin reagent ( $\mathrm{Vu}$ and Le 2010). $\mathrm{pH}$ values of fermentation batch was determined at different interval of time using $\mathrm{pH}$ meter. Dry cell weight analysis was done by the method of (Wen et al. 2015).

\section{Statistics analysis}

For the fitted experimental results of RSM, regression method of response surface was used. Coded values represented the variables according to the equation:

$$
\mathrm{Xi}=(\mathrm{Xi}-\dot{\mathrm{X}} \mathrm{i}) / \mathrm{Xi}=1,2,3 \ldots \mathrm{K}
$$


Table 1 Experiment design and results of optimization of nutrient medium for the production of secondary metabolites from Streptomyces 1123 by the central composite design

\begin{tabular}{|c|c|c|c|c|c|c|c|c|}
\hline \multirow[t]{2}{*}{ Run no. } & \multirow[t]{2}{*}{$x_{1}$} & \multirow[t]{2}{*}{$x_{2}$} & \multirow[t]{2}{*}{$x_{3}$} & \multirow[t]{2}{*}{$X_{4}$} & \multirow[t]{2}{*}{$x_{5}$} & \multicolumn{2}{|c|}{ Inhibition zone $(\mathrm{mm})$} & \multirow[t]{2}{*}{ Residual value } \\
\hline & & & & & & Observed & Predicted & \\
\hline 1 & 4 & 4 & 0.4 & 0.4 & 0.04 & 30.5 & 32.0341 & 0.80684 \\
\hline 2 & 8 & 8 & 0.8 & 0 & 0 & 18.9 & 20.1345 & 1.52224 \\
\hline 3 & 4 & 12 & 0.4 & 0.4 & 0.04 & 20 & 21.3111 & 1.56492 \\
\hline 4 & 4 & -4 & 0.4 & 0.4 & 0.04 & 22 & 19.2044 & 1.56492 \\
\hline 5 & 0 & 0 & 0 & 0 & 0.08 & 13.8 & 16.1961 & 1.52224 \\
\hline 6 & 12 & 4 & 0.4 & 0.4 & 0.04 & 23 & 21.4044 & 1.56492 \\
\hline 7 & 8 & 8 & 0 & 0.8 & 0 & 23 & 21.0378 & 1.52224 \\
\hline 8 & 0 & 8 & 0.8 & 0 & 0.08 & 20.2 & 19.4878 & 1.52224 \\
\hline 9 & 4 & 4 & 1.2 & 0.4 & 0.04 & 21 & 19.4811 & 1.56492 \\
\hline 10 & 0 & 8 & 0.8 & 0.8 & 0 & 18.5 & 16.8995 & 1.52224 \\
\hline 11 & 8 & 8 & 0 & 0 & 0.08 & 14 & 13.8661 & 1.52224 \\
\hline 12 & 4 & 4 & 0.4 & 0.4 & 0.04 & 33.5 & 32.0341 & 0.80684 \\
\hline 13 & 8 & 0 & 0 & 0.8 & 0.08 & 11 & 10.9545 & 1.52224 \\
\hline 14 & 4 & 4 & 0.4 & 0.4 & 0.12 & 24.3 & 22.2777 & 1.56492 \\
\hline 15 & 0 & 0 & 0.8 & 0.8 & 0.08 & 22.1 & 21.9161 & 1.52224 \\
\hline 16 & 0 & 8 & 0 & 0 & 0 & 4.5 & 4.9795 & 1.52224 \\
\hline 17 & 0 & 0 & 0 & 0.8 & 0 & 12 & 12.4078 & 1.52224 \\
\hline 18 & 4 & 4 & 0.4 & 0.4 & 0.04 & 33.67 & 32.0341 & 0.80684 \\
\hline 19 & 0 & 8 & 0 & 0.8 & 0.08 & 5.34 & 5.7511 & 1.52224 \\
\hline 20 & 4 & 4 & 0.4 & 0.4 & 0.04 & 30.35 & 32.0341 & 0.80684 \\
\hline 21 & 4 & 4 & 0.4 & 0.4 & 0.04 & 32.7 & 32.0341 & 0.80684 \\
\hline 22 & 4 & 4 & 0.4 & 0.4 & -0.04 & 18.5 & 19.0377 & 1.56492 \\
\hline 23 & 8 & 0 & 0 & 0 & 0 & 2.0 & 1.8628 & 1.52224 \\
\hline 24 & -4 & 4 & 0.4 & 0.4 & 0.04 & 17.1 & 17.2111 & 1.56492 \\
\hline 25 & 0 & 0 & 0.8 & 0 & 0 & 3.0 & 3.0645 & 1.52224 \\
\hline 26 & 8 & 0 & 0.8 & 0.8 & 0 & 20.3 & 22.2228 & 1.52224 \\
\hline 27 & 4 & 4 & 0.4 & 1.2 & 0.04 & 15 & 15.6944 & 1.56492 \\
\hline 28 & 4 & 4 & -0.4 & 0.4 & 0.04 & 8.43 & 8.4644 & 1.56492 \\
\hline 29 & 4 & 4 & 0.4 & 0.4 & 0.04 & 30 & 32.0341 & 0.80684 \\
\hline 30 & 8 & 8 & 0.8 & 0.8 & 0.08 & 10 & 11.1461 & 1.52224 \\
\hline 31 & 8 & 0 & 0.8 & 0 & 0.08 & 13.6 & 16.2511 & 1.52224 \\
\hline 32 & 4 & 4 & 0.4 & -0.4 & 0.04 & 11.25 & 9.0711 & 1.56492 \\
\hline
\end{tabular}

Coded values; $X_{1}$ peanut meal, $X_{2}$ soluble starch, $X_{3} \mathrm{NaCl}, X_{4}$ yeast, $X_{5}$ ammonium sulphate

where $x_{i}$ is an independent variable coded value, $X_{i}$ is the independent variable's real value, $\mathrm{X}$ is the independent variable's real mean, and $X_{i}$ is the step change value. The second-order polynomial model was fitted a response curve fitting the equation;

$$
\mathrm{Y}=\mathrm{b} 0+\sum \mathrm{bixi}+\sum \mathrm{i} \sum \mathrm{j} \text { bij xi xj }+\sum \text { bii xi, }
$$

where $\mathrm{Y}$ is stand for measurement of response; the intercept term indicated by b0; bi, bij and bii are measures of the effects of variables xi, xixj and xi respectively.
The variable xixj represents the first-order interaction between $x i$ and $x j(i<j)$. Analysis of variance (ANOVA) was used for the statistical analysis of the model, that comprising of the Fisher's F-test, associated probability $P(F)$, determination coefficient $R^{2}$ and correlation coefficient $R$ that measures the goodness of fit regression model. The analysis also included Student's t-value for the estimated coefficients and associated probabilities, $\mathrm{P}(\mathrm{t})$. For each variable, the quadratic models were represented as contour plots (Gao et al. 2016; Ahsan et al. 2017a). 


\section{Results}

Effect of carbon, nitrogen and microelement sources on antifungal activity of Strain KX852460

Peanut meal, wheat bran, soya bean meal and soluble starch were used as carbon and nitrogen source. Effects of concentrations of these carbon and nitrogen sources in the medium on the antifungal activity were determined. By increasing the concentrations of peanut meal and soluble starch from 0 to $14 \%$, the diameter of inhibition zone increased (Fig. 1a, d), while the antifungal effects of wheat bran and soya bean meal were not significant. Increasing the concentrations of wheat bran and soya bean meal from 0 to $14 \%$, the diameter of inhibition zone was observed not increased as compared to peanut meal and soluble starch (Fig. 1b, c).

Yeast extract and peptone were added in the medium as additional nutrients. Yeast extract had significant antifungal effects, as the concentration increased from 0 to $1.6 \%$ (Fig. $2 \mathrm{a}$ ). While the peptone was investigated with the same concentration and results showed not too much influenced on antifungal activity (Fig. 2b). Four microelements were screened for the maximum production of antibiotic, to the disease management of target spot on tobacco leaf and suppressing the pathogen R. solani AG-3. Ammonium sulfate, calcium carbonate, sodium chloride, and magnesium sulphate with same concentration of each ranges from 0 to $1.4 \%$. Ammonium sulfate and sodium chloride had significant effects on the antifungal activity of strain KX852460 (Fig. 3a, c). Calcium carbonate and magnesium sulphate had no significant effects on the antifungal activity against $R$. solani AG-3 by the strain KX852460 (Fig. 3b, d). On the base of results and keeping in view the cost of the experiment, following nutrients i.e. peanut meal, soluble starch, yeast extract, sodium chloride, and ammonium sulphate were screened for the optimization of fermentation medium.

\section{Optimization of fermentation medium through CCD}

The antifungal effects of antibiotic, produced by $S$. diastatochromogenes KX852460 were maximized by optimization of the medium components through central composite design (CCD) of response surface
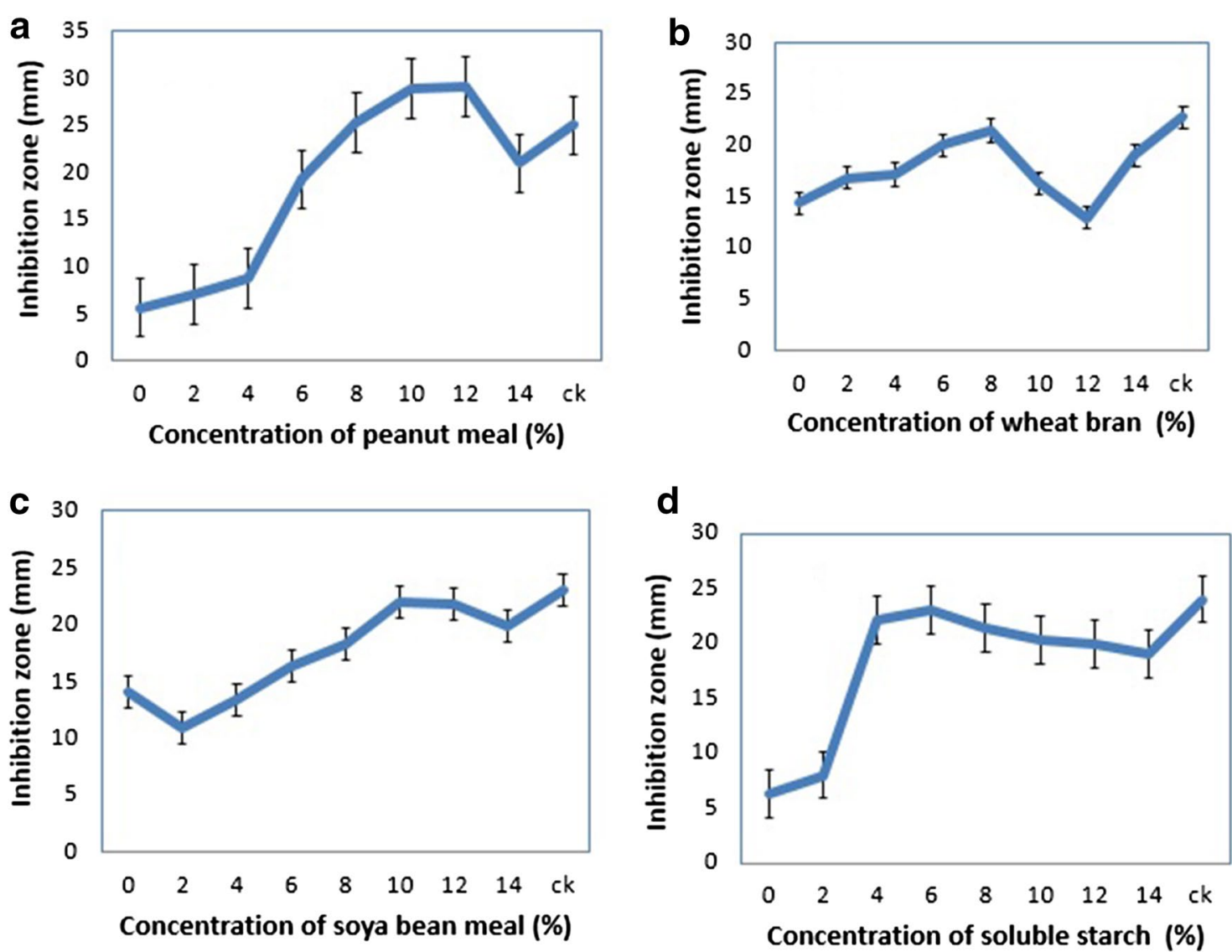

Fig. 1 Antifungal effects of nitrogen and carbon sources at different concentrations against the R. solani AG-3, other nutrients kept at their original concentrations. a Peanut meal, b wheat bran, c soya bean, and $\mathbf{d}$ soluble starch 


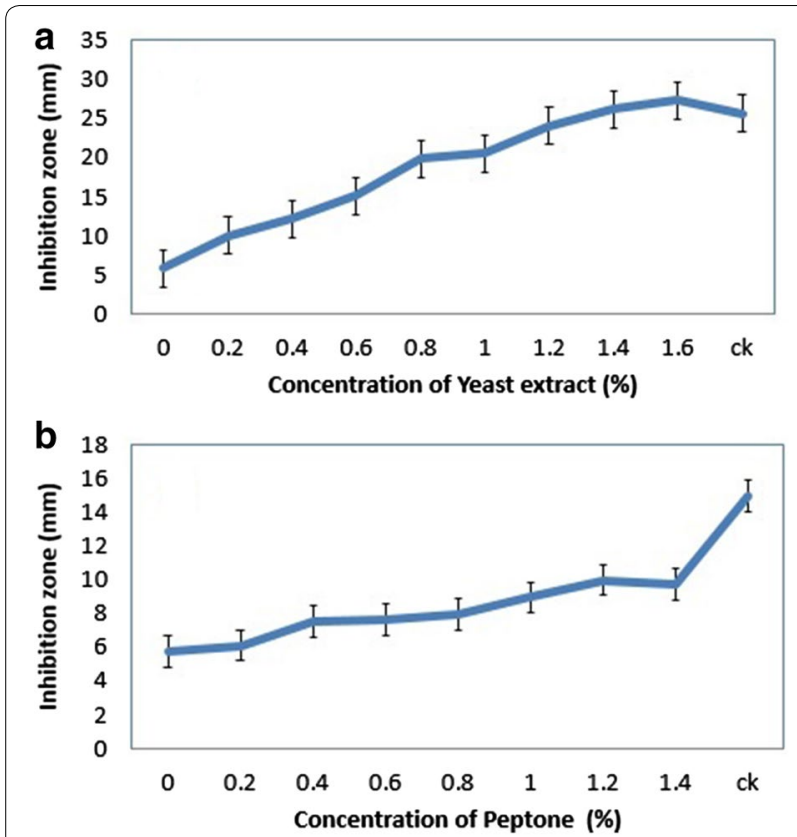

Fig. 2 Antifungal effects of supplement compounds at different concentration against the $R$. solani AG-3, other nutrients kept at their original concentrations. a Yeast extract, and $\mathbf{b}$ peptone

methodology. Thirty-two experiments were conducted in triplicate with different concentrations of Peanut meal, soluble starch, $\mathrm{NaCl}$, yeast extract and ammonium sulfate (Table 1). The response obtained from experiments of central composite design (Table 2) were calculated with second order polynomial multiple regression Eq. 3.

Antifungal activity $(\mathrm{Y})$

$$
\begin{aligned}
= & -2.44+2.129 \mathrm{X}_{1}+2.400 \mathrm{X}_{2}+29.46 \mathrm{X}_{3} \\
& +43.13 \mathrm{X}_{4}+375.2 \mathrm{X}_{5}-0.1988 \mathrm{X}_{1}^{2} \\
& -0.1840 \mathrm{X}_{2}^{2}-28.22 \mathrm{X}_{3}^{2}-30.71 \mathrm{X}_{4}^{2} \\
& -1778 \mathrm{X}_{5}^{2}+0.0834 \mathrm{X}_{1} \mathrm{X}_{2}-15.25 \mathrm{X}_{1} \mathrm{X}_{5} \\
& -1.319 \mathrm{X}_{2} \mathrm{X}_{4}-15.06 \mathrm{X}_{2} \mathrm{X}_{5}-228.7 \mathrm{X}_{4} \mathrm{X}_{5}
\end{aligned}
$$

where $\mathrm{Y}$ is the response (antibiotic activity); and $\mathrm{X}_{1}, \mathrm{X}_{2}$, $\mathrm{X}_{3}, \mathrm{X}_{4}$ and $\mathrm{X}_{5}$ are the coded values of the independent factors, viz., Peanut flour, soluble starch, $\mathrm{NaCl}$, yeast and ammonium sulfate respectively.

Analysis of variance (ANOVA) was performed on data collected from experiments as shown in the Table 3. The proposed model for this study was found significant having Fischer test value of 39.21 and $P$ value of 0.000 . The coefficient of determination $R^{2}$ showed the appropriateness of the adequate model. $R^{2}$ values

\begin{tabular}{|c|c|c|c|c|c|}
\hline Source & DF & Adj SS & Adj MS & F-value & $P$ value \\
\hline Model & 15 & 2406.84 & 160.456 & 39.21 & 0.000 \\
\hline Linear & 5 & 296.63 & 59.327 & 14.50 & 0.000 \\
\hline$x_{1}$ & 1 & 26.38 & 26.376 & 6.45 & 0.022 \\
\hline$x_{2}$ & 1 & 6.66 & 6.657 & 1.63 & 0.220 \\
\hline$x_{3}$ & 1 & 182.05 & 182.050 & 44.49 & 0.000 \\
\hline$x 4$ & 1 & 65.80 & 65.803 & 16.08 & 0.001 \\
\hline$x_{5}$ & 1 & 15.75 & 15.746 & 3.85 & 0.067 \\
\hline Square & 5 & 1607.94 & 321.588 & 78.59 & 0.000 \\
\hline$x_{1}^{2} x_{1}$ & 1 & 296.93 & 296.927 & 72.56 & 0.000 \\
\hline$X_{2}^{2} X_{1}$ & 1 & 254.25 & 254.252 & 62.13 & 0.000 \\
\hline$x_{3}^{2} x_{3}$ & 1 & 598.06 & 598.057 & 146.15 & 0.000 \\
\hline$X_{4}^{2} X_{4}$ & 1 & 707.99 & 707.990 & 173.02 & 0.000 \\
\hline$x_{5}^{2} X_{5}$ & 1 & 237.27 & 237.273 & 57.99 & 0.000 \\
\hline 2-way interaction & 5 & 502.27 & 100.453 & 24.55 & 0.000 \\
\hline$x_{1}^{2} x_{2}$ & 1 & 28.52 & 28.516 & 6.97 & 0.018 \\
\hline$x_{1}^{2} x_{5}$ & 1 & 95.26 & 95.258 & 23.28 & 0.000 \\
\hline$X_{2}^{2} x_{4}$ & 1 & 71.23 & 71.234 & 17.41 & 0.001 \\
\hline$x_{2}^{2} x_{5}$ & 1 & 92.93 & 92.930 & 22.71 & 000.0 \\
\hline$x_{4}^{2} x_{5}$ & 1 & 214.33 & 214.330 & 52.38 & 0.000 \\
\hline Error & 16 & 65.47 & 4.092 & & \\
\hline Lack-of-fit & 11 & 51.24 & 4.658 & 1.64 & 0.306 \\
\hline Pure error & 5 & 14.23 & 2.846 & & \\
\hline Total & 31 & 2472.31 & & & \\
\hline
\end{tabular}
also determined the trail parameters, their interaction and showed unpredictability in the response. In this study coefficient determination $\mathrm{R}^{2}=0.9735$ or $97.35 \%$
Table 2 Analysis of variance of antifungal activity

indicated that about $2.65 \%$ variations were not determined by the model. The adjusted determination coefficient $\mathrm{R}^{2}=0.9487$ or $94.87 \%$ also showed that the model was highly significant.

All the linear term regression coefficients showed great impact on the antibiotic activity according to the significance of corresponding $\mathrm{p}$-values $\left[\mathrm{pX} \mathrm{X}_{1}=0.022\right.$, $\mathrm{pX}_{2}=(0.022), \mathrm{pX}_{3}=(0.000), \mathrm{pX} 4=(0.001)$, and $\left.\mathrm{pX}_{5}=(0.067)\right]$. Peanut flour, soluble starch, $\mathrm{NaCl}$, yeast and ammonium sulfate showed their great effect during the activity of the antibiotic. Quadric coefficient of $\mathrm{X}_{11}$, $\mathrm{X}_{22}, \mathrm{X}_{33}, \mathrm{X}_{44}$, and $\mathrm{X}_{55}$ were significant and negative effect of these quadrants determined that amplifying the activity of the antibiotic as the parameter's values enlarged and decreased as the parameter values increased above from certain values. Interactive terms coefficients of $X_{12}$, $\mathrm{X}_{15}, \mathrm{X}_{24}$ and $\mathrm{X}_{45}$ were significant. Predicted and actual values of the medium and zone of inhibition against the fungus were given in the (Fig. 4).

Regression models generated surface plots to determine the impact of independent variables and interactive effect of each variable. Signification of variables directly related to the shape of each surface plot that the reciprocal interactions among the independent variables. Figures $5 a-f, 6 a-d$ shown the activity for each pair of 

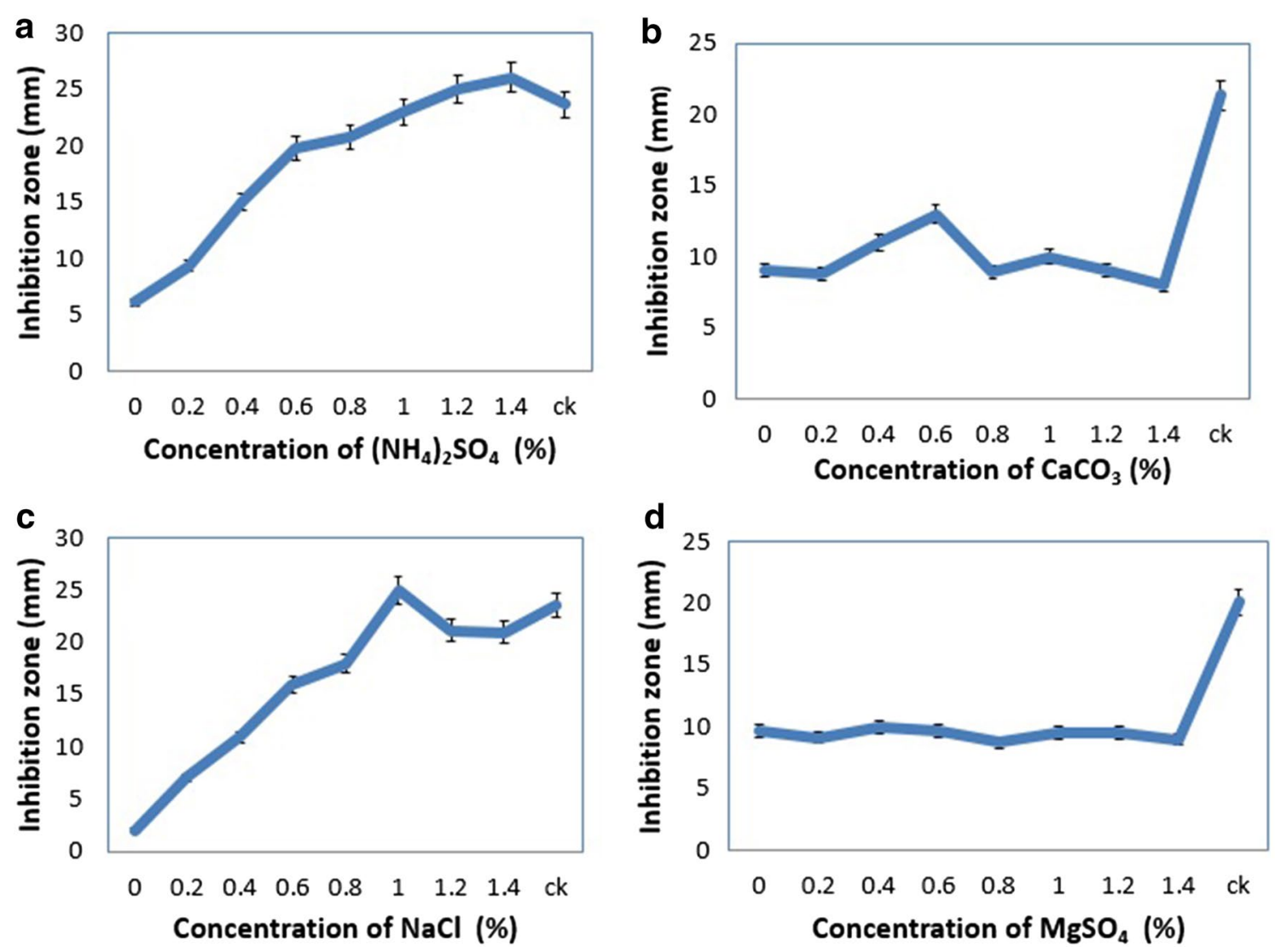

Fig. 3 Antifungal effects of microelements against the R. solani AG-3 a ammonium sulfate, $\mathbf{b}$ calcium carbonate, $\mathbf{c} \mathrm{NaCl}$, and $\mathbf{d}$ magnesium sulfate

variables and kept the others constant at their middle values.

\section{Metabolism of Streptomyces diastatochromogenes KX852460 during fermentation in shaking flasks}

During the fermentation process evaluation of total sugar, reducing sugar, amino nitrogen, $\mathrm{pH}$ and dry mycelium weight was done The total sugar was utilized; at initial stages the concentration of total sugar was high, within the time utilization of total sugar was increased and concentration of total sugar was decreased. At initial stages, the consumption was low, as the total sugar was utilized gradually, concentration of reducing sugar increased, and after $96 \mathrm{~h}$ decreased abruptly. Amino nitrogen level was up and down, while $\mathrm{pH}$ values was also not stable and remained between 5.5 and 6.6 in the whole process of fermentation. Dry mycelium weight was increased within the hours of fermentation process, after $84 \mathrm{~h}$ the weight of dry mycelium was highest, while it became decreased after $120 \mathrm{~h}$ of fermentation (Table 4).

\section{Discussion}

For the production of antibiotics from the microbes, microelements are very crucial. Several phenomenons including physiologically and synthetically were affected by the concentrations of microelements ( $\mathrm{CaO}$ and $\mathrm{Ma}$ 2002). On the base of antifungal activity against the R. solani AG-3, peanut meal and soluble starch were selected for the optimized carbon and nitrogen source for the production of antibiotic in the fermentation medium respectively. Several studies revealed that growth and bioactivity of microbe were greatly affected by the constitution of the substrate medium, such as carbon, nitrogen sources and inorganic microelements (Purama and Goyal 2008; Rao et al. 2007; Song et al. 2007). Current study reveals that yeast extract and peptone had impact on the activity of antibiotic against the R. solani AG-3. In the complex fermentation composition yeast extract and peptone had great influence on the production of actinorhodin by Streptomyces coelicolor A3 (2) (Elibol 2004). To find optimize parameters 
response surface methodology is suitable mathematical and statistical tool; it can be helpful to find experimental design for illuminating the relations between the different parameters. Recently RSM was used extensively to optimize fermentation parameters (Bankar and Singhal 2010; Purama and Goyal 2008; Song et al. 2007). Later total sugar, reducing sugar and amino nitrogen level in the fermentation batch decreased, while at the same time growth of bacteria increased. As the total sugar, reducing sugar, and amino nitrogen consumed by the Streptomyces strain. The rate of growth of Streptomyces strain was declined due to accumulation of secondary metabolites and other metabolites in fermentation batch and $\mathrm{pH}$ became decreased. By the utilization of total sugar, the level of reducing sugar decreased, positively effect on $\mathrm{pH}$ value and negatively effect on the dry mycelium that led to increase the synthesis of fermentation product ( $\mathrm{Li}$ et al. 2002). S. diastatochromogenes KX852460 had good antifungal effects against the $R$. solani AG-3 to combat the target spot disease on tobacco leaves. Peanut meal, soluble starch, $\mathrm{NaCl}$, yeast extract, and ammonium sulphate were optimized ingredients for the high antifungal activity of secondary metabolites. This product could be good fungicide for the biological disease management of target spot and other $R$. solani related disease.

Table 3 Coded coefficients for antifungal activity

\begin{tabular}{|c|c|c|c|c|c|c|}
\hline Term & Effect & Coef & SE Coef & T-value & $P$-value & VIF \\
\hline Constant & & 32.034 & 0.807 & 39.70 & 0.000 & \\
\hline$X_{1}$ & 2.097 & 1.048 & 0.413 & 2.54 & 0.022 & 1.00 \\
\hline$x_{2}$ & 1.053 & 0.527 & 0.413 & 1.28 & 0.220 & 1.00 \\
\hline$x_{3}$ & 5.508 & 2.754 & 0.413 & 6.67 & 0.000 & 1.00 \\
\hline$X_{4}$ & 3.312 & 1.656 & 0.413 & 4.01 & 0.001 & 1.00 \\
\hline$x_{5}$ & 1.620 & 0.810 & 0.413 & 1.96 & 0.067 & 1.00 \\
\hline$x_{1}^{2} X_{1}$ & -6.363 & -3.182 & 0.373 & -8.52 & 0.000 & 1.02 \\
\hline$x_{2}^{2} x_{2}$ & -5.888 & -2.944 & 0.373 & -7.88 & 0.000 & 1.02 \\
\hline$x_{3}^{2} x_{3}$ & -9.031 & -4.515 & 0.373 & -12.09 & 0.000 & 1.02 \\
\hline$x_{4}^{2} x_{4}$ & -9.826 & -4.913 & 0.373 & -13.15 & 0.000 & 1.02 \\
\hline$x_{5}^{2} x_{5}$ & -5.688 & -2.844 & 0.373 & -7.61 & 0.000 & 1.02 \\
\hline$x_{1}^{2} x_{2}$ & 2.670 & 1.335 & 0.506 & 2.64 & 0.018 & 1.00 \\
\hline$x_{1}^{2} x_{5}$ & -4.880 & -2.440 & 0.506 & -4.82 & 0.000 & 1.00 \\
\hline$x_{2}^{2} x_{4}$ & -4.220 & -2.110 & 0.506 & -4.17 & 0.001 & 1.00 \\
\hline$x_{2}^{2} x_{5}$ & -4.820 & -2.410 & 0.506 & -4.77 & 0.000 & 1.00 \\
\hline$X_{4}^{2} X_{5}$ & -7.320 & -3.660 & 0.506 & -7.24 & 0.000 & 1.00 \\
\hline
\end{tabular}

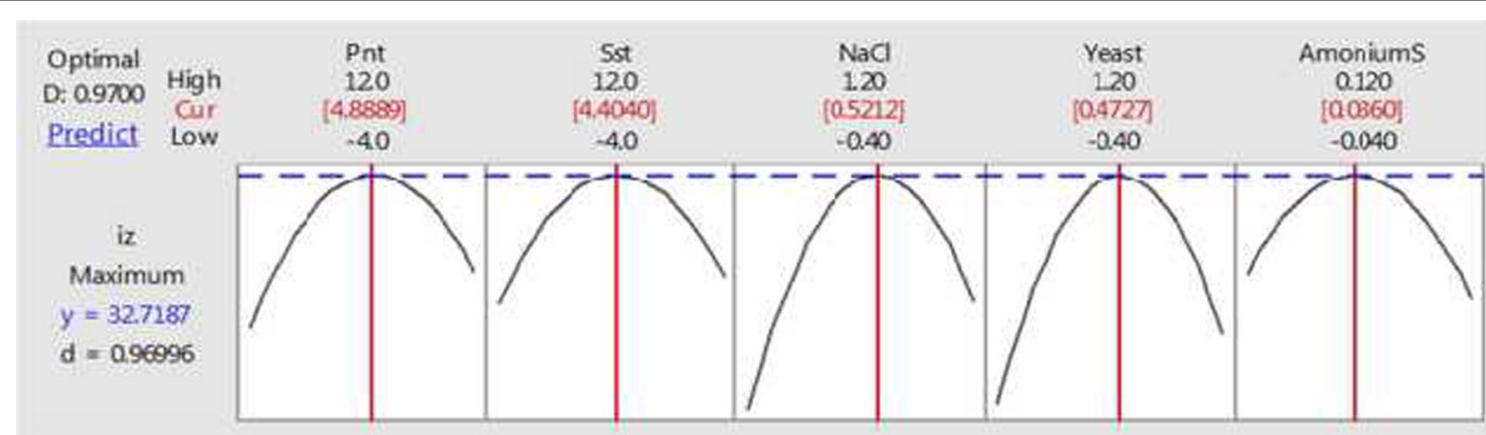

Fig. 4 Predicted and actual values of media composition and inhibition zone against the R. solani AG-3 


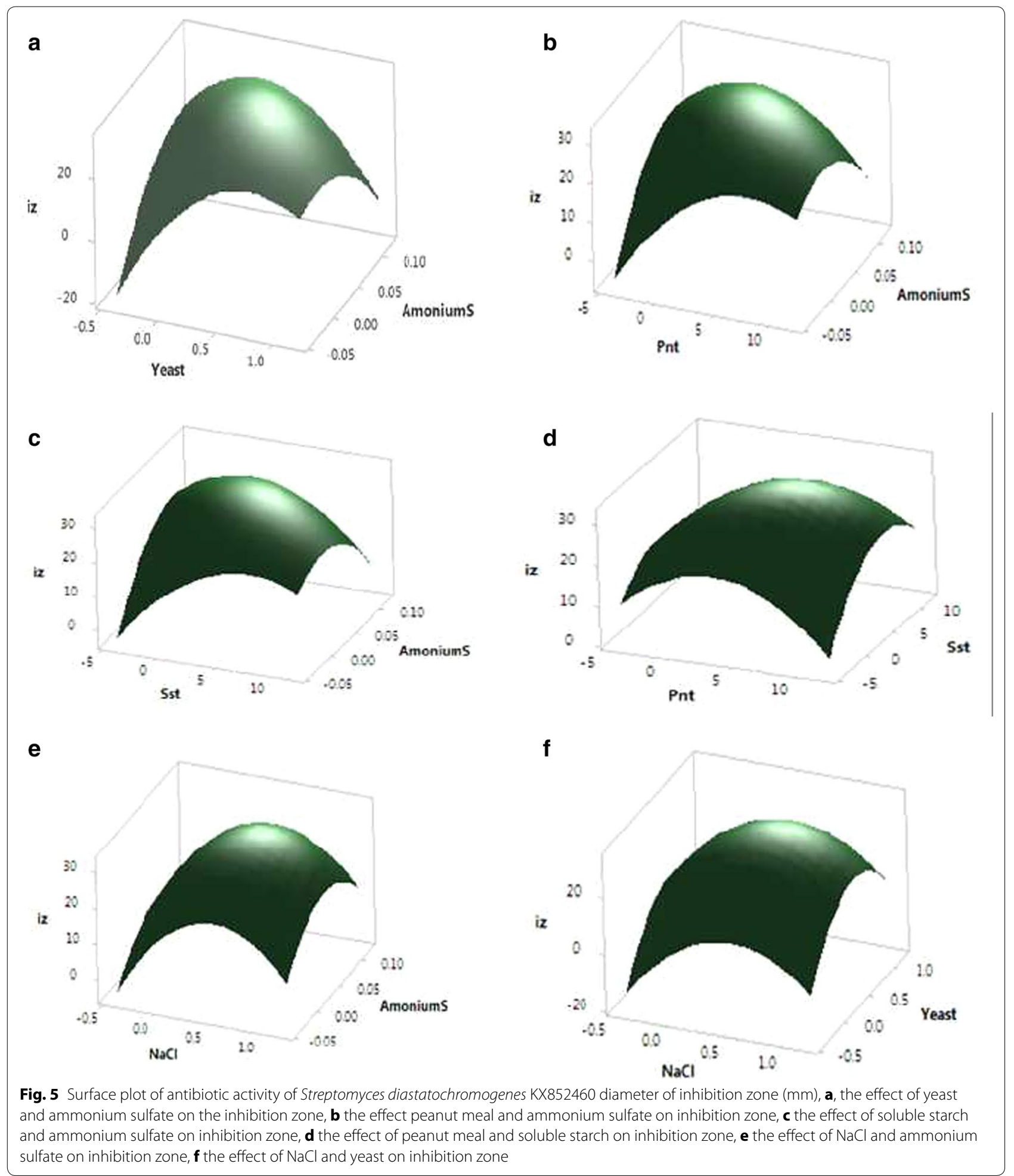



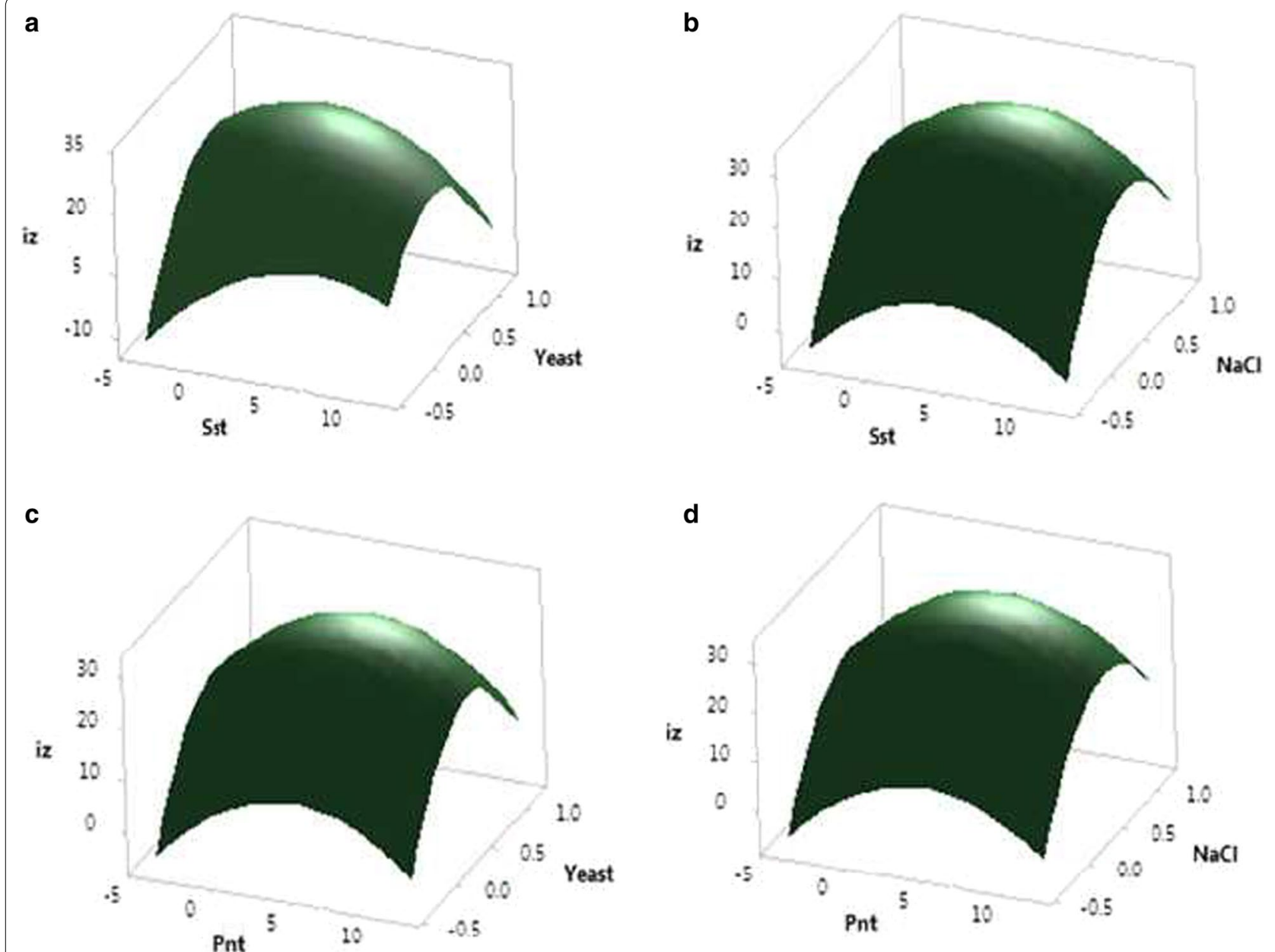

Fig. 6 Surface plot of antibiotic activity of Streptomyces diastatochromogenes KX852460 diameter of inhibition zone ( $\mathrm{mm}$ ), a the effect of soluble starch and yeast on the inhibition zone, $\mathbf{b}$ soluble starch and $\mathrm{NaCl}$ on the inhibition zone, $\mathbf{c}$ the effect of peanut meal and yeast on inhibition zone, and $\mathbf{d}$ the effect of peanut meal and $\mathrm{NaCl}$ on inhibition zone

Table 4 Metabolism study of submerged fermentation batch produced by Streptomyces diastatochromogenes KX852460

\begin{tabular}{|c|c|c|c|c|c|c|c|c|c|c|c|}
\hline \multirow[t]{2}{*}{ Parameters } & \multicolumn{11}{|c|}{ Culture time (h) } \\
\hline & 0 & 12 & 24 & 36 & 48 & 60 & 72 & 84 & 96 & 108 & 120 \\
\hline Total sugar (mg/ml) & 87.3 & 79.3 & 75.6 & 64.2 & 51.5 & 39.0 & 35.0 & 28.0 & 20.7 & 13.1 & 12.3 \\
\hline Reducing sugar (mg/ml) & 0 & 3.4 & 4.4 & 5.3 & 15.9 & 18.8 & 20.0 & 17.8 & 15.1 & 9.0 & 9.0 \\
\hline Amino nitrogen (mg/ml) & 0.55 & 0.66 & 0.60 & 0.61 & 0.59 & 0.49 & 0.37 & 0.14 & 0.14 & 0.10 & 0.10 \\
\hline $\mathrm{pH}$ value & 6.6 & 6.3 & 6.5 & 6.5 & 6.5 & 6.5 & 5.9 & 6.0 & 5.9 & 5.6 & 5.5 \\
\hline Dry mycelium weight (mg/ml) & 0 & 4.4 & 7.0 & 15.2 & 20.0 & 20.9 & 21.3 & 23.2 & 21.3 & 20.9 & 19.5 \\
\hline
\end{tabular}

\section{Abbreviations}

RSM: response surface methodology; CCD: central composite design; CGMCC: Chinese general microbial culture collection.

\section{Authors' contributions}

Planning and designing of study: YW; Experimentation: TA; Result Analysis: JC, Manuscript Drafting and literature survey: MI. All authors contributed in the final approval of manuscript. All authors read and approved the final manuscript.
Author details

${ }^{1}$ Department of Plant Pathology, Plant Protection College, Shenyang Agricultural University, Shenyang, People's Republic of China. ${ }^{2}$ Department of Biotechnology, University of Sargodha, Sargodha, Pakistan.

\section{Acknowledgements}

The authors are thankful to the technical staff of the Department of Plant Pathology, College Plant Protection, Shenyang Agricultural University, P. R. China. 


\section{Competing interests}

The authors declare that they have no competing interests.

\section{Availability of data and materials}

Data regarding microbe is available in public database like NCBI and CGMCC.

\section{Ethical approval}

No data was used in this article which needs approval.

\section{Funding}

This study is supported by Project Number 183/2010 from Liaoning research center of tobacco China.

\section{Publisher's Note}

Springer Nature remains neutral with regard to jurisdictional claims in published maps and institutional affiliations.

Received: 9 March 2017 Accepted: 21 April 2017

Published online: 15 May 2017

\section{References}

Ahsan T, Chen J, Wu Y, Irfan M, Shafi J (2017a) Screening, identification, optimization of fermentation conditions, and extraction of secondary metabolites for the biocontrol of Rhizoctonia Solani AG-3. Biotechnol Biotechnol Equip 31:1-8. doi:10.1080/13102818.2016.1259016

Ahsan T, Chen J, Zhao X, Irfan M, Wu Y (2017b) Extraction and identification of bioactive compounds (Eicosane and Dibutyl phthalate) produced by Streptomyces strain KX852460 for the biological control of Rhizoctonia solani AG-3 strain KX852461 to control target spot disease in tobacco leaf. AMB Expr 7:54. doi:10.1186/s13568-017-0351-z

Al-Hulu S (2013) Study effects of some parameters on antifungal activity for Streptomyces spp. J Kerbala Uni 11:3

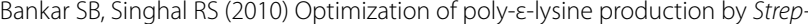
tomyces noursei NRRL 5126. Biores Technol 101:8370-8375. doi:10.1016/j. biortech.2010.06.004

Cao J, Ma H (2002) Microbial engineering. Science Press, Beijing

Clardy J, Fischbach MA, Walsh CT (2006) New antibiotics from bacterial natural products. Nat Biotechnol 24:1541-1550. doi:10.1038/nbt1266

Demain AL, Sanchez S (2009) Microbial drug discovery, 80 years of progress. Antibiot 62:5-16. doi:10.1038/ja.2008.16

dos Reis Almeida FB, Cerqueira FM, do Nascimento Silva R, Ulhoa CJ, Lima AL (2007) Mycoparasitism studies of Trichoderma harzianum strains against Rhizoctonia solani: evaluation of coiling and hydrolytic enzyme production. Biotechnol Lett 2:1189-1193. doi:10.1007/s10529-007-9372-z

Dubois M, Gilles KA, Hamilton JK, Rebers PA, Smith F (1956) Colorimetric method for determination of sugars and related substances. Anal Chem 28:350-356

Elibol M (2004) Optimization of medium composition for actinorhodin production by Streptomyces coelicolor A3 (2) with response surface methodology. Proc Biochem 39:1057-1062. doi:10.1016/s0032-9592(03)00232-2

El-Mehalawy AA, Abd-Allah N, Mohammed R, Abu-Shady M (2005) Actinomycetes antagonizing plant and human pathogenic fungi, II. Factors affecting antifungal production and chemical characterization ofthe active components. Int J Agric Biol 7:188-196
Gao X, He Q, Jiang Y, Huang L (2016) Optimization of nutrient and fermentation parameters for antifungal activity by Streptomyces lavendulae Xjy and its biocontrol efficacies against Fulvia fulva and Botryosphaeria dothidea. J Phytopathol 164:155-165. doi:10.1111/jph.12440

Grahovac J, Grahovac M, Dodić J, Bajić B, Balaž J (2014) Optimization of cultivation medium for enhanced production of antifungal metabolites by Streptomyces hygroscopicus. Crop Prot 65:143-152. doi:10.1016/j. cropro.2014.07.020

Kong Y, Zou P, Miao L, Qi J, Song L, Zhu L (2014) Medium optimization for the production of anti-cyanobacterial substances by Streptomyces sp. HJC-D1 using response surface methodology. Environ Sci Pollut Res 21:59835990. doi:10.1007/s11356-014-2532-5

Kumar M, Singh A, Beniwal V, Salar RK (2016) Improved production of tannase by Klebsiella pneumoniae. AMB Expr 6:1-11. doi:10.1186/ S13568-016-0217-9

Li XM, Li Y, Li PR (2002) The relations among reducing sugar, pH, dry weight of mycelium and production during the liquid fermentation of Marasmius androsaceus". Edible Fungi China 21:37-38

Miller GL (1959) Use of dinitrosalicylic acid reagent for determination of reducing sugar. Anal Chem 31:426-428. doi:10.3181/00379727-20-47

Nouby M, Mathivanan D, Srinivasan K (2009) A combined approach of complex eigenvalue analysis and design of experiments (DOE) to study disc brake squeal. Int J Eng Sci Tech 1:254-271. doi:10.4314/ljest.v1|1.58084

Purama RK, Goyal A (2008) Screening and optimization of nutritional factors for higher dextransucrase production by Leuconostocmesenteroides NRRL B-640 using statistical approach. Biores Technol 99:7108-7114. doi:10.1016/j.biortech.2008.01.032

Rao YK, Tsay K-J, Wu W-S, Tzeng Y-M (2007) Medium optimization of carbon and nitrogen sources for the production of spores from Bacillus amyloliquefaciens B128 using response surface methodology. Proc Biochem 42:535-541. doi:10.1016/j.procbio.2006.10.007

Scherlach K, Hertweck C (2009) Triggering cryptic natural product biosynthesis in microorganisms. Org Biomol Chem 7:1753-1760. doi:10.1039/ b821578b

Song X, Zhang X, Kuang C, Zhu L, Guo N (2007) Optimization of fermentation parameters for the biomass and DHA production of Schizochytrium limacinum OUC88 using response surface methodology. Proc Biochem 42:1391-1397. doi:10.1016/j.probio.2007.07.014

Vu T, Le V (2010) Using fed-batch fermentation in high-gravity brewing: effects of nutritional supplementation on yeast fermentation performance. Int Food Res J 17:117-126

Wen Z, Liu Z, Hou Y, Liu C, Gao F, Zheng Y, Chen F (2015) Ethanol induced astaxanthin accumulation and transcriptional expression of carotenogenic genes in Haematococcus pluvialis. Enzyme Microb Technol 78:10-17. doi:10.1016/J.enzmictec.2015.06.010

Wu YH, Zhao YQ, Fu Y, Zhao XX, Chen JG (2012) First report of target spot of flue-cured tobacco caused by Rhizoctonia solani AG-3 in China. Plant Dis 96:1824. doi:10.1094/pdis-06-12-0551.pd4

\section{Submit your manuscript to a SpringerOpen ${ }^{\odot}$ journal and benefit from:}

- Convenient online submission

- Rigorous peer review

- Immediate publication on acceptance

- Open access: articles freely available online

- High visibility within the field

- Retaining the copyright to your article

Submit your next manuscript at springeropen.com 